\title{
Issues Affecting the Adoption and Usage of Mobile Instant Messaging in Semi-Rural Public Schools of South Africa for Learning
}

\author{
Nkhangweni Lawrence Mashau \\ Tshwane University of Technology, Pretoria, South Africa \\ Email: Mashau.lawrence@gmail.com
}

How to cite this paper: Mashau, N.L. (2016) Issues Affecting the Adoption and Usage of Mobile Instant Messaging in SemiRural Public Schools of South Africa for Learning. Open Access Library Journal, 3: e3156.

http://dx.doi.org/10.4236/oalib.1103156

Received: October 18, 2016

Accepted: November 5, 2016

Published: November 9, 2016

Copyright $\odot 2016$ by author and Open Access Library Inc.

This work is licensed under the Creative Commons Attribution International

License (CC BY 4.0).

http://creativecommons.org/licenses/by/4.0/

\section{(c) (i) Open Access}

\begin{abstract}
Mobile instant messaging technologies have become popular among the youth, they predominantly use it to socialise, communicate and share information anywhere and anytime and it provides the platform which learners can use for learning from specialists across the world. This study was conducted in semi-rural schools in the Vhembe District in Limpopo Province of South Africa. Diffusion of innovation theory was used to determine factors that could promote the adoption of mobile instant messaging for learning mathematics in semi-rural public schools. IBM SPSS Statistics 20 for analysis was used to analyze data. However, learners in most semi-rural public schools in South Africa appear not to be aware of mobile instant messaging for learning and are not adopting and using it despite its availability and convenience. It was also found that most learners and educators never used mobile instant messaging for learning, because they had never heard of it. Lack of awareness of mobile instant messaging was found as one of the factors hindering learners to adopt mobile instant messaging for learning in South African semi-rural public schools.
\end{abstract}

\section{Subject Areas}

Education

\section{Keywords}

Adoption, DOI, Learning, Mathematics, Mobile Instant Messaging

\section{Introduction}

Mobile Instant Messaging (MIM) is an asynchronous application that works on a wireless network that allows students and peers to chat in real time by using their mobile 
phones. MIM is anonymous and collaborative learning applications which allow shy, less confident students to participate more productively online [1]. MIM is an internet based application which provides real time chat by means of text messages, voice and video among people [2].

MIM is an online chat platform which offers instant text transmission over the cell phone network. MIM is a set of communication technologies used for text-based communication between two or more users over the cell phone networks. MIM chat happens in real time. More advanced MIM can add file transfer, clickable hyperlinks, voice chat, and video chat [3]. The most used MIM applications in South Africa are: Mxit, WhatsApp, weChat, eBuddy, Viber, Yahoo! Messenger, Facebook, Skype, and BBM [4]. The use of MIM by youth is becoming increasingly popular, and has become an object of communication for many people.

The structure of this paper is in the following manner: The first segment discusses the introduction and gives the synopsis of MIM. The second segment discusses the broad overview of MIM issues in semi-rural schools in South Africa. The third segment discusses the theoretical framework employed to support this paper. The forth segment covers the research approach followed to write this paper. The fifth segment discusses the results and the sixth section concludes the discussion.

\section{Background}

This paper focused on the learners from semi-rural secondary public schools in the Limpopo Province, South Africa. This research explored issues affecting the adoption of MIM for learning mathematics to improve pass rates and learners marks. MIM is used on a cell phone for social bonding and education between learners and teachers [3].

South Africa mathematics pass rate since 2011 to 2014 does not look good. In year 2011, 224,636 learners wrote mathematics and 1,040,033 learners attained 30\% and above that makes it a pass, which contribute to $46.3 \%$, in year 2012, 225,874 learners wrote mathematics and 121,970 learners attained $30 \%$ and above that makes it a pass, which amount to 54\% pass rate in 2012. In the year 2013, 241,509 learners wrote mathematics, but 142,666 learners attained $30 \%$ and above which contribute to a pass, which make 59.1\% pass rate in South Africa for the year 2013 and in year 2014, 225,458 learners wrote mathematics and 120,523 learners attained 30\% and above that makes it a pass, which amount to $53.5 \%$ pass rate in 2014. Therefore, South Africa Department of Education attained 53.2\% in average between the year 2011 and the year 2014 [5]. South Africa has a deficiency of highly qualified teachers, particularly in mathematics in rural public schools [6].

South Africa is a diverse nation, with a population estimated at 54 million people as of July 2014 [7]. It has been reported that $82 \%$ of South African young people between age of 15 and 24 have cell phones. The young people are early adopters of MIM technologies such as WhatsApp, BBM, Mxit, Facebook, Twitter and Skype on their cell phones [8]. MIM services are mostly cheaper and easy to use, making them affordable 
and attractive for most users from disadvantaged backgrounds [2]. Learning using MIM on a cell phone can solve the issue of shortage of the qualified teachers on the key subjects in the Semi-rural schools in South Africa.

\section{Theory for Evaluating the Adoption and Usage of Mobile Instant Messaging}

In this section, the Diffusion of Innovation Theory [9], is used to establish the theoretical foundation for this study. The Diffusion of Innovation (DOI) Theory is used in this research to establish the factors which will aid the learners to use MIM for learning in order to improve their mathematics knowledge, skills and their marks. The variables were then used to develop an MIM adoption model and to create hypotheses based on the research model which helped to understand the issues affecting the adoption of MIM for learning mathematics in semi-rural public schools.

As argued in the preceding section, learners may use MIM for learning mathematics to improve their mathematics results. The argument presented in the preceding section presented MIM as a potential platform to assist learners to enhance their way of learning mathematics in semi-rural public schools.

This section presents the DOI Theory as the theoretical framework underpinning this study to assist learners to adopt MIM for learning to improve their skills, knowledge and their marks.

\section{Diffusion of Innovation}

According to Shi, diffusion of innovation is the most well-known theory and model in technology adoption [10]. Rogersdefines diffusion of innovation as the process by which an innovation is communicated among the member of a social system through certain channels over time [9].

Diffusion of innovation is regarded as a multi-disciplinary theory that has been widely used to explain information systems adoption researches. There are five primary factors that have an impact on the rate of adoption. According to the DOI theory, they are: relative advantage, complexity, compatibility, trialability, and observability [9].

- Relative Advantage: is the degree to which an innovation is perceived as better than the idea it replaces [9]. It should be noted that the relative advantage of an innovation is closely associated with an individual perception. Whether a user believes the innovation as advantageous is more important than whether an innovation has an objective advantage over the precedent idea [9].

The greater the perceived relative advantage of an innovation, the more rapid its adoption will be [10]. MIM offers learners greater control to ask questions in order to get assistance with their mathematics homework [11]. Learners can access Mxit on their cell phone to learn mathematics at their convenient time [12]. With all this relative advantages of MIM, it would be expected that learners from semi-rural public schools would be likely to adopt this service.

- Compatibility: is the degree to which an innovation is perceived as being consistent 
with the existing values, past experiences, and needs of potential adopters [9]. An idea that is incompatible with the values and norms of a social system will not be adopted as rapidly as an innovation that is compatible. The adoption of an incompatible innovation often requires the prior adoption of a new value system which is a relatively slow process [10]. A study conducted by Gerrand and Cunningham, shows that compatibility is an important factor which influences the adoption of innovation [13].

- Complexity: is the degree to which an innovation is perceived as difficult to understand and use [9]. New ideas that are simpler to understand are adopted more rapidly than innovations that require the adopter to develop new skills and understandings [10]. MIM has a user-friendly interface which would give learners a perception that instant messaging services are less complex to use for learning; thus it would promote learners intention to adopt these innovations [14]. The adoption will be less likely if the innovation such as MIM is considered as complicated to use and not user friendly [15].

- Trialability: is the degree to which an innovation may be experimented with within a limited basis [9]. The theory suggests that, innovations that are experimented will be likely to be adopted more quickly than innovations that are not tried. This is due to the decreased uncertainty gained by experimenting [9]. An innovation that is tried represents less uncertainty to the individual who is considering it for adoption, who can learn by doing [10]. The research indicated that if the users are given the opportunity to try new innovations, it would reduce the apprehension towards the usage of the new innovations. The study conducted by [16], showed that trialability has a significant influence on new technology adoption.

- Observability: is the degree to which the results of innovations are visible to others [9].This observability stimulates discussion around the innovation as the peer group requests evaluation information about the innovation. The theory suggests that, the more individuals see observable results of an innovation, the more they are likely to adopt it [9].

- Awareness: is the degree to which the users are aware of the new innovation, know how it works and what its objectives are. Shiindicates that lack of awareness among people may become a barrier to the adoption of an innovation [10]. The study conducted by Al-Jabri and Sohail, shows that awareness plays an important role in the influence of the adoption of the new innovations [11].

\section{Development of Hypothesis}

Hypotheses were developed based on the Diffusion of Innovation theory. According to Shi, awareness is a better predictor of the intention to adopt new innovation [10], while triability is a better predictor of intention of inexperienced users to adopt new innovations. This research used the awareness as an external variable affecting the learners' adoption of MIM for learning in semi-rural public schools in South Africa. 


\section{Mobile Instant Messaging Adoption Model}

This research used DOI theory to assist the researcher to investigate issues affecting students to adopt MIM for learning in semi-rural public schools to improve their marks. The DOI theory supports the objective of the research which is to investigate issues that will influence the adoption of MIM for learning in semi-rural public schools.

Figure 1 shows a research model that was used to analyse issues affecting adoption of MIM in South African semi-rural public schools for learning. Therefore, this research uses all five constructs of diffusion of innovation theory and awareness because it provides an important framework to support this research. The adoption of MIM will assist learners to improve their mathematics marks and the pass rate in South Africa.

\section{Hypotheses}

This research has hypothesised Relative Advantage, Compatibility, Complexity, Trialability, Observability, and Awareness for the adoption of mobile instant messaging for learning in semi-rural public schools. There are six hypotheses that have been drawn from the research objectives and question of this study:

- Hypotheses 1: Relative advantage of mobile instant messaging will positively influence the use of mobile instant messaging for learning in South Africa semi-rural public schools.

- Hypotheses 2: Compatibility of mobile instant messaging with the culture of learning will positively affect learners to use mobile instant messaging for learning in South Africa semi-rural public schools.

- Hypotheses 3: Complexity will affect learners negatively to use mobile instant messaging for learning in South Africa semi-rural public schools.

- Hypotheses 4: Trialability of mobile instant messaging will positively influence learners to use mobile instant messaging for learning in South Africa semi-rural public schools.

- Hypotheses 5: Observability will affect learners' behaviour towards using mobile instant messaging for learning in South Africa semi-rural public schools.

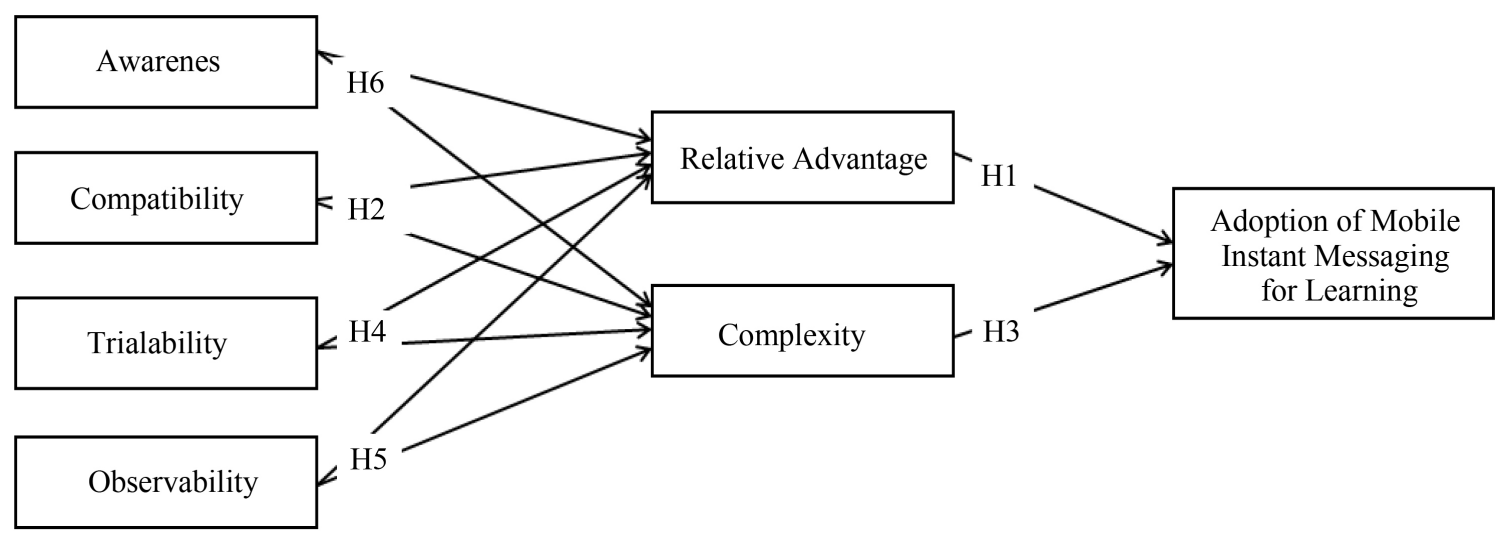

Figure 1. Modified diffusion of innovation theory [10]. 
- Hypotheses 6: Awareness of mobile instant messaging for learning affects the adoption and use of mobile instant messaging positively in South Africa semi-rural public schools.

\section{Research Methodology}

This study employed quantitative methodology because this study used questionnaires to aggregate attribute from a large set of the population. The qualitative approach relies primarily on human narrative and understanding, while the quantitative approach is used to aggregate attributes from a very large set of users [12]. Quantitative methods typically involve a procedure to quantify phenomena, association or relationship between variables as well for approving or disapproving the hypothesis. A quantitative method uses questionnaires in surveys to collect data from the respondents. Quantitative research is a thinking that relies heavily on linear variables, calculations and statistical analysis [13]. This research will use a quantitative methodology for investigating the factors influencing the use of instant messaging in South African rural public schools.

A paradigm is an integrated set of beliefs, assumption, models of doing research, and techniques for collecting and analysing data [14]. This research will be based on the positivist paradigm. Positivism is used to describe a philosophical position that can be discerned in research and can also involve crude and superficial data collection [15]. This study is directed at investigating factors that will influence learners to use MIM for learning in semi-rural public schools. According to Welman and Kruger, the positivist approach is the study of observable human behaviour and requires a research design to be decided before data collection [17].

\section{Research Design}

Mouton, defines a research design as a blueprint or plan on how one aim to conduct the research [18]. This research is based on descriptive research in order to answer questions such as "why" and "how". This will enable information to be gathered from any given sample of the population. The population group for this study included Grade 12 learners who took mathematics as a subject and the educators who taught mathematics in Limpopo Province semi-rural public schools.

A survey it was conducted in the Limpopo province in South Africa. To support the purpose of this research, a quantitative research approach was applied by using a questionnaire to collect data. According to Sekaran, a questionnaire allows researchers to obtain empirical data from a large population, in a simple and inexpensive way [19]. All questions were closed-ended questions.

Participants of this study were purposively selected based on the performance of the public schools in the rural areas in Limpopo Province, Vhembe district. The researcher select low performing schools in mathematics to find out why are they not taking advantage of technology to improve their way of learning and their results. This schools where selected because is were the problems are and affect the provincial results. The 
reason why the high perfoming schools were not selected is because, the researcher wanted to find how the low perfoming schools can improve their results using technology to close all the gaps faced by schools in rural areas. The criterion used to select the schools, the reseach choose the schools with low percentage pass rate in mathematics. Participants in this research included educators who taught mathematics as a subject and learners who took mathematics as a subject in Grade 12.

The instrument used for collecting data was closed-ended questionnaire. The instrument used for this research it was divided into three sections. That is, Section A which was about demographic details of the participants and this included status, gender, age, number of years using cell phone and the connection of the cellphone to the internet. Section B included questions that check the usage of the MIM and number of years. Then, Section $C$ included questions which were based on five-point Likert scale ranging from 1 (strongly disagree) to 5 (strongly agree).

Data collection took place in May and August 2015. In total, 400 questionnaires were distributed by the researcher to 13 schools in the Vhembe district in the semi-rural areas in Limpopo Province in South Africa. Out of the 400 questionnaires distributed, 288 were returned and 112 were not returned. Out of the 288 responses received, 86 were not usable, and 202 were usable.

Before starting with data analysis, screening of questionnaires were performed and after that data preparation was conducted by means of coding and editing the collected data. Editing is the process of making sure that the questionnaires were completed by the respondents according to instructions [20] [21]. Coding refers to a plan of grouping and assigning numeric codes recognising different answers to specific questions. In this research, the coding, editing and capturing of data was done by using Microsoft Excel and then uploaded on IBM SPSS Statistics 20 for analysis.

\section{Results and Analysis}

Comparison between learners and educators who are using and not using mobile instant messaging tools for learning was conducted. Status, gender, age, cellphone experience and cell phone that support the mobile instant messaging tools were considered. Table 1 shows the status of the respondents, of the returned 202 questionnaires which were usable, 166 respondents used the cellphone that support instant messaging tools and 36 respondents, their cell phone did not support instant messaging tools. Out of the 202, 98 were male and 104 were female.

Respondents' experience using MIM are presented as follows: Most of the respondents [114 (56.4\%)] showed that they have used MIM compared to eighty-eight [88 (43.6\%)] who have never used MIM. As to the reasons why the respondents are not using MIM, Figure 2, shows that the majority of respondents [37 (41.6\%)] indicated that they do not like MIM, [28 (31.5\%)] stated that their cell phones does not support MIM, [12 (13.5\%)] respondents said they have not heard of MIM applications, [11 (12.4\%)] respondents said they do not feel safe using MIM and [1 (1.1\%)] respondent does not have a cell phone. This means $54.6 \%$ of learners who used MIM are likely to adopt 
Table 1. Demographic data.

\begin{tabular}{ccc}
\hline Characteristics & Frequency & Percent (\%) \\
\hline Status & & \\
Learners & 188 & $93.1 \%$ \\
Educators & 14 & $6.9 \%$ \\
Gender & & \\
Male & 98 & $48.5 \%$ \\
Female & 104 & $51.5 \%$ \\
Age & & \\
17 to 20 years & 179 & $88.6 \%$ \\
21 to 30 years & 8 & $4.0 \%$ \\
31 to 40 years & 2 & $1.0 \%$ \\
41 to 50 years & 1 & $0.5 \%$ \\
51 to 60 years & 11 & $5.4 \%$ \\
61 to 65 years & 1 & $0.5 \%$ \\
Cell phone experience & & \\
None & & $1.5 \%$ \\
1 to 2 years & 3 & $16.3 \%$ \\
3 to 4 years & 33 & $28.2 \%$ \\
5 to 6 years & 57 & $18.3 \%$ \\
7 or more & 37 & $35.6 \%$ \\
Yell phone access to the instant messaging & 72 & \\
Yes & & \\
No & 166 & \\
\hline
\end{tabular}

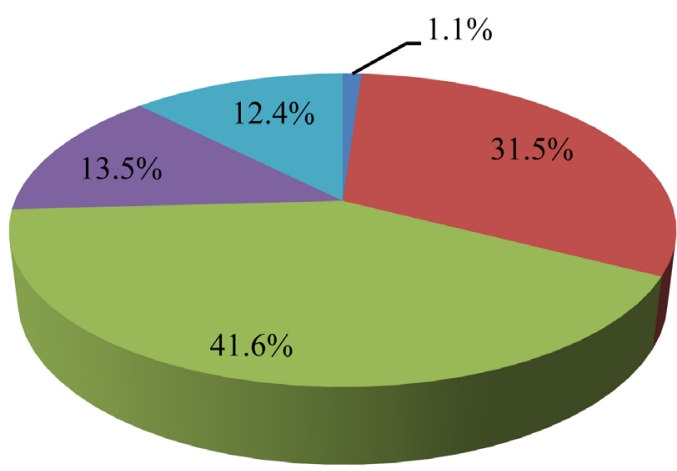

- I don't have a cell phone

- My cell phone does not support mobile instant messaging applications

I don't like mobile instant messaging applications

I have not heard about mobile instant messaging applications

I don't feel safe using mobile instant messaging applications

Figure 2. Reason for not using mobile instant message applications.

MIM for learning because they have seen the relative advantage of using MIM and 43.6\% may adopt MIM for learning later after they have been trained. As indicated in Figure 3, the experience of using MM was distributed as follows: [88 (43.6\%)] respondents had no MIM experience, compared to [83 (41.1\%)] respondents, who had 1 to 2 years of experience, [17 (8.4\%)] respondents had 3 to 4 years of experience, [10 (5.0\%)] respondents had 5 to 6 years of experience and [4 (2.0\%)] respondents had 7 or more years of experience.

As indicated in Figure 4, most of the respondents [88 (43.6\%)] has showed that they 


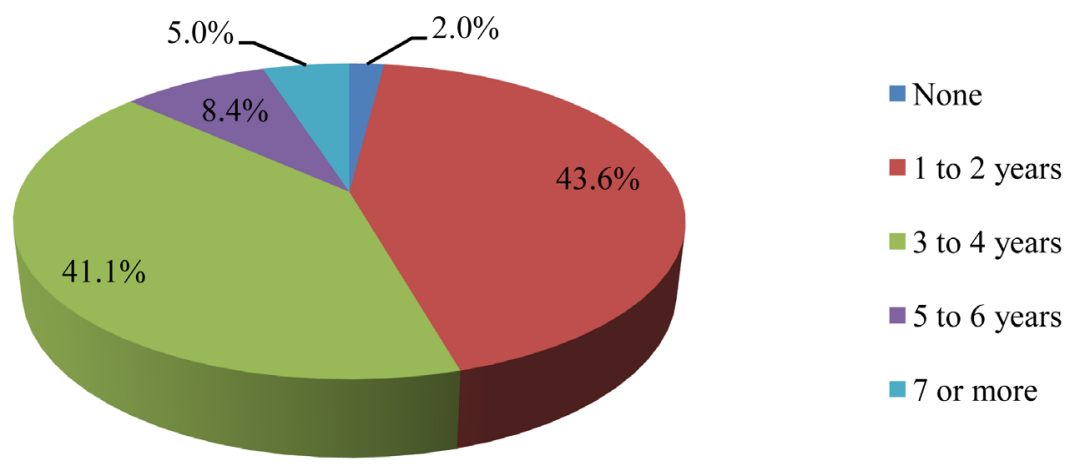

Figure 3. Experience using mobile instant messaging applications.

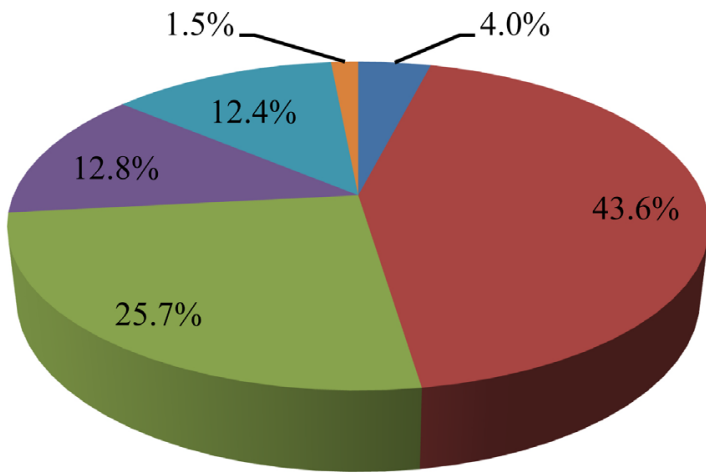

None

Daily

Weeky

- Monthly

Q Quarterly

Yearly

Figure 4. Mobile instant messaging application usage frequency.

do not use MIM at all, while [52 (25.7\%)] of the respondents showed that they use it daily, [26 (12.8\%)] of the respondents showed that they used it weekly, [25 (12.4\%)] of the respondents showed that they used it monthly, [3 (1.5\%)] respondents showed that they used it quarterly and $[8(4.0 \%)]$ respondents showed that they used it yearly. The majority of respondents [106 (95.5\%)] indicated that they use MIM for communicating with friends and family, while [5 (4.5\%)] indicated that they use MIM for learning. This research is supported by the study previously conducted by Butgereit and Botha, which presented that most youth have experience of using MIM on their cell phones [13].

Most of the respondents [194 (96.0\%)] showed that they have never used MIM for learning compared to [8 (4.0\%)] respondents who showed that they have used MIM for learning. This study is contrary to the previous research conducted by Robbinswhich indicated that most learners have experience using MIM for learning [22]. [6 (75\%)] respondents who used MIM indicated that they learned about it from newspapers or magazines and [2(25\%)] respondents who used MIM indicated that they learned about it from friends or relatives. One hundred and eighty-three [183 (94.3\%)] respondents who never used MIM indicated that they have not heard about it, [4 (2.1\%)] respondents indicated that there is no need for MIM for learning, they prefer learning in the classroom, [3 (1.5\%)] respondents indicated that it takes more of their time; [2 (1.0\%)] respondents indicated that it does not help them with learning; and [2 (1.0\%)] respondents indicated that the cost of using MIM is high. This means that there is no enough 
awareness about the use of IM for learning in the semi-rural public schools.

In this study, six hypotheses were formulated. Beta and significance of the regression analysis model were used to test hypothesis by regressing each independent, moderating variable against the dependent variable which is the adoption of MIM for learning (Table 2).

The finding from this research indicates that the intention to adopt MIM for learning can be projected by trialability, observability and awareness, but not relative advantage, compatibility and complexity.

Relative advantage (Hyp1) is not supported. The hypothesis stated that relative advantage affects the intention to adopt and use MIM for learning in South African rural public schools. The rejection of this variable as the possible predictor of the adoption or use of MIM for learning was due to the fact that most learners were unsure about the advantages of using MIM for learning because the majority of respondents (96.0\%) had never used MIM for learning. The relative advantage of using MIM for learning was not realised because most respondents do not know about this readily available cell phone application. Therefore, learners do not know these benefits, such as learning wherever they are, during their convenient time, asking questions regarding their mathematics problems and receiving guidance from the tutos on how to solve their mathematics problems by using MIM for learning.

Compatibility (Hyp2) is not supported. The compatibility variable is not supported as one of the potential predictors of the adoption of MIM for learning in South African semi-rural public schools. Based on the results, the majority of respondents do not know about using MIM for learning and they were uncertain about the compatibility of using MIM for learning with their cultural way of learning. The correlation results show that the compatibility construct has a weak positive relationship to the intention of adopting MIM for learning $\left(r=0.240^{* *}, p<0.001\right)$. When learners start identifying any compatibility of using MIM with the cultural way of learning in South African semi-rural public schools, the more learners will be likely to adopt MIM for learning.

Complexity (Hyp3) is not supported. It has been shown in this research that complexity has a negative effect on the adoption of MM for learning in semi-rural public schools. Rogers, claims that if the latest innovation is difficult to use, then would be less likely to be adopted faster [9]. The more learners use MIM for learning and understand how it works and feel comfortable with it, the chances of learners adopting MIM for

Table 2. Hypothesis acceptance and rejection test notes.

\begin{tabular}{ccccc}
\hline Hypothesis & Variables & Beta & $\boldsymbol{P}$-Value & Notes \\
\hline Hyp1 & Relative Advantage & 0.058 & 0.558 & Not Supported \\
Hyp2 & Compatibility & -0.053 & 0.590 & Not Supported \\
Hyp3 & Complexity & 0.076 & 0.288 & Not Supported \\
Hyp4 & Trialability & 0.270 & 0.000 & Supported \\
Hyp5 & Observability & 0.267 & 0.000 & Supported \\
Hyp6 & Awareness & 0.306 & 0.000 & Supported \\
\hline
\end{tabular}


learning in South African semi-rural public schools will improve.

Trialability (Hyp4) is supported. It has been shown in this research that trialability of MIM for learning may positively promote the adoption of MIM for learning in South African semi-rural public schools. Even though the scope is not the same, the support is in line with the outcome from the study conducted by Hernandez and Mazzon which highlights that trialability has an important influence on the adoption of the new technology [23]. Trialability of instant messaging for learning may improve the economy in the future because it will alleviate the gap of scarce skills. This may assist developing countries to improve their standard of education. The correlation results show that trialability has a strong positive relationship with the intention to adopt MIM for learning $\left(r=0.608^{* \star}, p<0.001\right)$. The more MM for learning becomes tested, the more learners would possibly adopt MIM for learning.

Observability (Hyp5) is supported. The hypothesis five states that observability influences the intention to adopt and use MIM for learning in South African rural public schools. The correlation results have shown that observability has a strong positive relationship with the intention of adopting MIM for learning $\left(r=0.698^{\star *}, p<0.001\right)$. The more observable benefits on the use of MIM for learning, the more learners in rural public schools would be likely to adopt MIM for learning.

Awareness (Hyp6) is supported. The hypothesis six states that awareness of MIM for learning will positively influence the adoption and use of MIM for learning in South African semi-rural public schools. The more learners are aware of MIM for learning in South African semi-rural public schools, the more they are likely to adopt MIM for learning. The regression results showed awareness as one of the important predictors to influence the adoption of MIM for learning in South African rural public schools. Research conducted by Polatoglu and Ekin, supports this by stating that users' knowledge has an influence on the adoption of new technology [24].

\section{Discussion and Conclusions}

This study sought to answer the following research problem: Why there is a significantly higher failure rate of mathematics in the South African semi-rural public schools, while there is this feature on MIM and the potential it has to assist learners to improve their mathematical knowledge and therefore, improve their results, why learners are not taking advantages of this readily available technology? The questions may apply to any country where technology is available, but it is not being adopted or used. The general conclusions of this research grounded on the outcome presented in the section above are as follows.

- The study finds that most of the learners in South African semi-rural public schools have cell phones which have an Internet connection and they use MIM on a daily basis. This has been found as the important factor to adopt MIM for learning.

- This study finds that learners are not aware of any benefit that MIM has for learning to improve their mathematics results.

- The findings of this study indicate that most respondents in South African semi- 
rural public schools have never used MIM for learning mathematics because they have never heard about the MIM application for learning.

- The finding of this research indicates that there is no enough awareness of using MIM for learning.

- The factors such as trialability, observability and awareness are found to have an important influence on the adoption of MIM for learning in South African semirural public schools. However, relative advantage, compatibility, and complexity are found not to be important factors in influencing the adoption of MIM for learning in South African semi-rural public schools.

- It is found that most of the respondents would like to try MIM application for learning on a trial basis to see any effect it may have on their marks.

- Findings show that the participants are likely to adopt MIM for learning in South African semi-rural public schools.

In this study, conclusions were drawn from demographic details, MIM usage and experience of the respondents and psychological elements which might influence learners to adopt instant messaging for learning. Lack of awareness for learning using MIM was found to be the greatest challenge which hampered learners in South African rural public schools to adopt instant messaging for learning by using MIM. A hypothesis test was conducted, three hypotheses were supported and the other three hypotheses were rejected during regression analysis. The trialability, observability and awareness were found to have a significant influence on the adoption of instant messaging for learning in South African semi-rural public schools.

\section{References}

[1] Patient, R. and Aaron, B. (2013) Using Mobile Instant Messaging to Leverage Learner. British Journal of Educational Technology, 44, 544 -561.

[2] Wei, W., Eric, W.N., Haiying, H. and Wei, L.C. (2012) Explaining Instant Messaging Continuance Intention: The Role of Personality. International Journal of Human Computer Interaction, 28, 500-510. http://dx.doi.org/10.1080/10447318.2011.622971

[3] Kim, H., Lee, M. and Minjeong, K. (2014) Effects of Mobile Instant Messaging on Collaborative Learning Processes and Outcomes: The Case of South Korea. International Forum of Educational Technology \& Society (IFETS), 17, 31-42.

[4] South Africa Mobile Report (2014) A Survey of Desktop User's Attitude and Uses of Mobile Phone. Aib, Polokwane.

[5] Limpopo Basic Education (2014) School Performance Report Limpopo. Basic Education, Polokwanee.

[6] Graham, S. and Provost, L. (2012) Mathematics Achievement Gaps between Suburban Learners and Their Rural and Urban Peers Increases over Time. Carsey Institute, Issue Brief No. 52, 1-8.

[7] Statistics South Africa (2014) Mid-Year Population Estimates. Statssa, Pretoria.

[8] Beger, G. and Sinha, A. (2012) South Africa Mobile Generation. Study on South Africa Young People on Mobiles, 1-48.

[9] Rogers, E. (1995) Diffusion of Innovation. 4th Edition, Free Press, New York. 
[10] Shi, X. (2011) Exploring Factors that Hinder the Adoption of Mobile Services in China A Qualitative User Analysis with Special Focus on Mobile Financial Service. School of Economics, Aalto University, Finland.

[11] Al-Jabri, I.M. and Sohail, M.S. (2012) Mobile Banking Adoption: Application of Diffusion of Innovation Theory. Journal of Electronic Commerce Research, 13, 379-391.

[12] Butgereit, L. and Botha, R. (2012) Automated Topic Spotting Provides Added Efficiency in a Chat Based Tutoring Environment. IST Africa, South Africa, 1-11.

[13] Gerrand, P. and Cunningham, J. (2003) The Diffusion of Internet Banking among Singapore Consumer. International Journal of Bank Marketing, 21, 16-28. http://dx.doi.org/10.1108/02652320310457776

[14] Butgereit, L. (2011) Seven Characteristics of a Successful Virtual Volunteering Platform. IST Africa, South Africa.

[15] Rogers, E. (1983) Diffusion of Innovation. Free Press, New York.

[16] Hernandez, J. and Mazzon, J. (2007) Adoption of Internet Banking. Proposition and Implementation of an Integrated Methodology Approach. International Journal of Bank Marketing, 25, 72-88. http://dx.doi.org/10.1108/02652320710728410

[17] Haskis, B. and Botha, A. (2013) Identify Tag Word Counterparts for Dr. Math.

[18] Welman, J. and Kruger, S. (2001) Research Methodology. Oxford University Press, Cape Town.

[19] Mouton, J. (2001) How to Succeed in Your Master's and Doctoral Studies: A South African Guide and Resource Book. 13th Edition, Van Schaik, Pretoria.

[20] Sekaran, U. (2003) Research Methods for Business: A Skill-Building Approach. 4th Edition, John Wiley \& Sons, New York.

[21] McDaniel, C. and Gates, R. (2002) Marketing Research. South-Westeren, Singapore.

[22] Mokwena, S. (2011) Factors Influencing the Acceptance and Use of a School Administration and Management System in South African High Schools. Unpublished PhD Thesis, Tshwane University of Technology, Pretoria.

[23] Robbins, B. (2013) Extending the Dialogue: Interactional and Multimodal Strategies in Synchronous Mobile Mathematics Tutoring on Mxit. University of Cape Town, Cape Town.

[24] Polatoglu, V. and Ekin, S. (2001) An Empirical Investigation of the Turkish Consumers' Acceptance of Internet Banking Services. International Journal of Bank Marketing, 19, 156165. http://dx.doi.org/10.1108/02652320110392527 
Submit or recommend next manuscript to OALib Journal and we will provide best service for you:

- Publication frequency: Monthly

- 9 subject areas of science, technology and medicine

- Fair and rigorous peer-review system

- Fast publication process

- Article promotion in various social networking sites (LinkedIn, Facebook, Twitter, etc.)

- Maximum dissemination of your research work

Submit Your Paper Online: Click Here to Submit

Or Contact service@oalib.com 